\title{
FAKTOR-FAKTOR PENYEBAB PUTUS SEKOLAH DARI ANAK PETANI DAN NON-PETANI DI DESA SEA DAN DESA WAREMBUNGAN KECAMATAN PINELENG KABUPATEN MINAHASA
}

\author{
Vinny Briggita Mua \\ Elsje Pauline Manginsela \\ Jenny Baroleh
}

\begin{abstract}
This study aims to determine what factors are the cause of drop out of the children of farmers and non-farmers and whether there are differences in factors that cause drop out of the children of farmers and non-farmers. The analysis used in this research is by using descriptive analysis. This study was conducted from April to June 2017. This study used primary data and secondary data. Primary data was collected by direct interviews based on list of questions that have been prepared to the total respondents as many as 28 respondents. Method of sampling in this research use purposive sampling methods, they are children of farmer and not farmer with their parents. The results of this study indicate that the factors causing drop out of the children of farmers and non-farmers are: internal factors consisting of the will of the child itself and because children do not like school. External factors consisting of the economic condition of parents (unable to finance) and the social environment because affected with children who have dropped out of school first. At the parent level, both farmers and non-farmers, there is no difference in the reasons for dropping out. While at the level of children, both farmers and non-farmers children, there are different reasons for dropping out of school. Non-farmer children are because of internal factors: the willingness of children themselves while the child farmers are because of external factors are because the social environment. *eprm*
\end{abstract}

Keywords: drop out, children of farmers and non-farmers, Sea Village, Warembungan Village, Pineleng Sub-district, Minahasa Regency

\begin{abstract}
ABSTRAK
Penelitian ini bertujuan untuk mengetahui faktor-faktor apa saja yang menjadi penyebab putus sekolah dari anak petani dan non-petani dan apakahada perbedaan pada faktor-faktor yang menyebabkan putus sekolah dari anak petani dan non-petani. Analisis yang digunakan dalam penelitian ini yaitu dengan menggunakan analisis deskriptif.Penelitian ini dilaksanakan dari bulan April sampai bulan Juni 2017.Penelitian ini menggunakan data primer dan data sekunder. Data primer dikumpulkan dengan wawancara langsung berdasarkan daftar pertanyaan yang telah disiapkan pada responden sebanyak 28 responden.Metode pengambilan sampel dalam penelitian ini menggunakan metode purposive sampling, yaitu anak petani dan bukan petani bersama orangtuanya.Hasil penelitian ini menunjukkan bahwafaktor-faktor penyebab putus sekolah dari anak petani dan non-petaniyaitu: faktor internal yang terdiri dari kemauan anak itu sendiri dan karena anak tidak menyukai sekolah. Faktor eksternal yang terdiri dari kondisi ekonomi orangtua (tidak mampu membiayai) dan lingkungan social karena terpengaruh dengan anak yang sudah putus sekolah lebih dahulu.Ditingkat orang tua, baik petani maupun bukan petani, tidak ada perbedaan alasan putus sekolah yang dikemukakan.Sedangkan ditingkat anak, baik petani dan non-petani, terdapat perbedaan alasan putus sekolah.Anak non petani karena faktor internal yaitu: kemauan anak sendiri sedangkan anak petani karena faktor eksternal yaitu karena lingkungan sosial.
\end{abstract}

Kata Kunci: putus sekolah, anak petani dan non-petani,Desa Sea, Desa Warembungan, Kecamatan Pineleng, Kabupaten Minahasa 


\section{PENDAHULUAN}

\section{Latar Belakang}

Pendidikan merupakan suatu faktor yang sangat penting bagi setiap individu karena dengan adanya pendidikan maka dapat menciptakan sumberdaya manusia yang berkualitas.Salah satu hak asasi manusia adalah memperoleh pendidikan. Hal ini diatur dalam Pasal 28c ayat 1 UUD 1945 dalam Astuti, dkk (2011), yang menyatakan bahwa: "Setiap orang berhak mengembangkan diri melalui pemenuhan kebutuhan dasarnya, berhak mendapat pendidikan dan memperoleh manfaat dari ilmu pengetahuan dan teknologi, seni dan budaya, demi meningkatkan kualitas hidupnya dan demi kesejahteraan umat manusia." Pasal tersebut menegaskan bahwa pendidikan merupakan kesatuan yang tak bisa dilepaskan dari tiap diri manusia.Tiap individu membutuhkan pendidikan untuk dapat mengembangkan kemampuan serta meningkatkan mutu kehidupan dan martabat dirinya. Melalui pendidikan, tiap individu diharapkan dapat mengembangkan potensi diri guna memperoleh masa depan yang lebih baik bagi dirinya maupun orang lain di sekitarnya.

Menurut Liansyah (2014), pendidikan dasar wajib seorang anak adalah 9 tahun yaitu pendidikan SD dan SMP, apabila dilihat dari umur mereka yang wajib untuk sekolah yaitu anak pada usia 7 sampai 15 tahun namun pemerintah telah menetapkan bahwa seorang anak harus berpendidikan minimal 12 tahun atau sampai lanjutan tingkat atas (SMA) . Pendidikan adalah hak yang sangat fundamental dan wajib untuk dipenuhi dengan kerjasama dari orangtua, masyarakat dan pemerintah. Hal tersebut di atur dalam Undang-Undang pendidikan No.20 tahun 2003 tentang sistem pendidikan nasional pasal 34 ayat 1-3 telah ditetapkan bahwa :

1. Setiap warga negara yang berusia 6 tahun dapat mengikuti wajib belajar

2. Pemerintah dan pemerintah daerah menjamin terselenggaranya wajib belajar minimal pada jenjang pendidikan dasar tanpa memungut biaya.

3. Wajib belajar merupakan tanggung jawab negara yang diselenggarakan oleh lembaga pendidikan, pemerintah dan masyarakat.
Pemerintah telah menerapkan program pendidikan wajib belajar sembilan tahun dan sekolah gratis untuk masyarakat Indonesia guna untuk meningkatkan mutu pendidikan, selain itu pemerintah juga memberikan keringanan biaya berupa dana Bantuan Operasional Sekolah (BOS), beasiswa bagi masyarakat yang kurang mampu, dan Kartu Indonesia Pintar (KIP). Adanya kebijakan pemerintah tersebut seharusnya dapat meringankan beban para orangtua untuk menyekolahkan anak mereka hingga tamat.Namun program-program dari pemerintah tersebut belum sepenuhnya dapat mencegah terjadinya putus sekolah dalam masyarakat.

Menurut Mudyahardjo (2001), pendidikan adalah usaha sadar yang dilakukan oleh seseorang, keluarga, masyarakat, dan pemerintah melalui kegiatan bimbingan pengajaran dan latihan yang telah berlangsung di sekolah dan diluar sekolah sepanjang hayat untuk mempersiapkan peserta didik agar dapat memainkan peranan dalam berbagai lingkungan hidup secara tepat di masa yang akan datang. Untuk itu, keberhasilan pendidikan tidak hanya menjadi tugas pemerintah semata tetapi juga keluarga dan masyarakat agar turut berperan secara aktif dalam mempersiapkan generasigenerasi penerus bangsa yang kelak berguna bagi pembangunan pada masa yang akan datang (Dewi dkk, 2014).

Terputus sekolahnya seorang anak atau masyarakat, tentu saja suatu hal yang sebenarnya tidak dikehendaki bagi mereka yang mengalami, maupun orang lain yang secara langsung melihat kenyataan ini.

Berdasarkan uraian di atas maka peneliti tertarik melakukan penelitian tentang faktorfaktor penyebab putus sekolah antara anak petani dan non-petani di Desa Sea dan Desa Warembungan Kecamatan Pineleng Kabupaten Minahasa karena berdasarkan pengamatan sementara, masih banyak yang dijumpai anak yang mengalami putus sekolah.

\section{Perumusan Masalah}

Berdasarkan latar belakang yang telah dikemukakan, maka yang menjadi rumusan masalah dalam penelitian ini yaitu: Apa saja yang menjadi faktor penyebab putus sekolah antara anak petani dan non petani di Desa Sea dan Desa Warembungan Kabupaten Minahasa? 


\section{Tujuan Penelitian}

Tujuan penelitian ini yaitu untuk mengetahui:

1. Faktor- faktor apa saja yang menjadi penyebab putus sekolah antara anak petani dan non-petani di Desa Sea dan Desa Warembungan Kabupaten Minahasa.

2. Untuk mengetahui apakah ada perbedaan menyangkut faktor-faktor penyebab putus sekolah antara anak petani dan non petani.

\section{Manfaat Penelitian}

1. Meningkatkan pengetahuan tentang faktor-faktor penyebab putus sekolah antara anak petani dan non-petani.

2. Diharapkan bagi peneliti yang memiliki minat yang sama mendapat pengetahuan tentang faktor-faktor penyebab putus sekolah anatara anak petani dan nonpetani. Serta menjadi bahan studi bagi peneliti-peneliti selanjutnya dan juga referensi dalam melaksanakan penelitian selanjutnya.

3. Diharapkan menjadi bahan pertimbangan bagi penentu kebijakan demi meningkat mutu pendidikan

\section{METODOLOGI PENELITIAN}

\section{Waktu dan Tempat Penelitian}

Penelitian ini dilaksanakan selama tiga bulan yaitu dari bulan April sampai Juni tahun 2017, mulai dari persiapan sampai penyusunan laporan penelitian. Tempat penelitian dilaksanakan di Desa Sea dan Desa Warembungan, Kecamatan Pineleng, Kabupaten Minahasa.

\section{Metode Pengumpulan Data}

Metode pengumpulan data dalam penelitian ini, dengan cara mengambil data primer dan data sekunder. Data primer adalah data yang diperoleh secara langsung dari lapangan melalui wawancara dengan menggunakan daftar pertanyaan kepada anak putus sekolah dan orangtua anak putus sekolah antara anak petani dan non petani. Sedangkan data sekunder adalah data yang diperoleh dari kantor desa.

\section{Metode Pengambilan Sampel}

Populasi dalam penelitian ini adalah anak putus sekolah dan orangtua anak putus sekolah.Pengambilan sampel dalam penelitian ini menggunakan metode purposivesampling.Dengan jumlah responden sebanyak 28 responden yang terdiri atas 7 orang tua dan 7 orang anak dari keluarga petani dan 7 orang tua dan 7 orang anak dari keluarga non-petani.

\section{Konsepsi Pengukuran Variabel}

1. Karakteristik responden
a. umur responden (Tahun)

b. jenis kelamin $(\mathrm{L} / \mathrm{P})$

2. Faktor- faktor penyebab putus sekolah
a. Kurangnya kemauan anak untuk bersekolah
b. Tidak Menyukai Sekolah
c. Kondisi ekonomi keluarga ( Jumlah pendapatan orangtua / bulan)
d. Tingkat pendidikan orangtua ( SD, SMP dan SMA)
e. Lingkungan sosial
f. Jarak rumah dengan sekolah ( $\mathrm{KM}$ )

\section{Metode Analisis Data}

Penelitian ini merupakan penelitian deskriptif dengan pendekatan kuantitatif dan kualitatif. Data akan disajikan dalam bentuk tabel.

\section{HASIL DAN PEMBAHASAN}

\section{Deskripsi Wilayah Penelitian}

\section{Letak Wilayah Desa Sea dan Desa Warembungan}

Batas-batas wilayah Desa Sea yaitu :

Sebelah Timur :Desa Warembungan

Sebelah Barat : Desa Koha

Sebelah Utara :Desa Sea 1, Sea Mitra, Sea 2, dan Desa Kalasey

Sebelah Selatan: Hutan 
Batas wilayah Desa Warembungan Kecamatan Pineleng Kabupaten Minahasa yaitu:

Sebelah Timur : Desa Pineleng 2

Sebelah Barat : Desa Koha Agotey

Sebelah Utara : Desa Sea, Malalayang

Sebelah Selatan: Kelurahan Tinoor Kota

Tomohon

\section{Keadaan Demografi}

Desa Sea dan Desa Warembungan merupakan suatu desa yang berada di wilayah Kecamatan Pineleng Kabupaten Minahasa yang jumlah penduduknya sebanyak 5.327 untuk Desa Sea dan Desa Warembungan sebanyak4.958 jiwa.

\section{Penduduk Menurut Pendidikan}

Penduduk Desa Sea dan Desa Warembungan pada umumnya telah berpendidikan dan setiap pendidikan dari penduduk Desa Sea dan Desa Warembungan tentunya berbeda-beda.Tabel 1 dan Tabel 2 menunjukkan perincian jumlah penduduk berdasarkan tingkat pendidikan.

Tabel 1. Jumlah Penduduk MenurutTingkat Pendidikan di Desa Sea pada tahun 2016

\begin{tabular}{clcc}
\hline No & Tingkat Pendidikan & Jumlah & $\begin{array}{c}\text { Persentase } \\
(\%)\end{array}$ \\
\hline 1 & $\begin{array}{l}\text { Belum / Tidak } \\
\text { Sekolah }\end{array}$ & 759 & 14,2 \\
2 & SD & 715 & 13,4 \\
3 & SMP & 1766 & 33,2 \\
4 & SMA & 1829 & 34,4 \\
5 & Diploma/S1 & 258 & 4,8 \\
\hline & Total & 5327 & 100 \\
\hline
\end{tabular}

Sumber : Kantor Desa Sea 2016, diolah

Tabel 1 menunjukan bahwa sebagian besar penduduk Desa Sea sudah memperoleh pendidikan yang cukup dimana tingkat yang paling mendominasi adalah tingkat SMP dan SMA dengan presentase $33,2 \%$ dan $34,4 \%$. Kemudian diikuti oleh belum/tidak sekolah dengan persentase $14,2 \%$ kemudian diikuti oleh tingkat SD dengan persentase 13,4\%. Diikuti oleh tingkat Diploma/S1 dengan persentase $4,8 \%$.
Tabel 2. Jumlah Penduduk Menurut Tingkat Pendidikan di Desa Warembungan pada tahun 2012

\begin{tabular}{llll}
\hline No & $\begin{array}{l}\text { Tingkat } \\
\text { Pendidikan }\end{array}$ & Jumlah & $\begin{array}{c}\text { Persentase } \\
(\%)\end{array}$ \\
\hline 1 & SD & 1.413 & 46,23 \\
2 & SMP & 1.008 & 32,98 \\
3 & SMA & 463 & 15,15 \\
4 & Diploma & 15 & 0,5 \\
5 & Sarjana (S1, S2, S3) & 157 & 5,14 \\
\hline \multicolumn{2}{l}{ Total } & $\mathbf{3 . 0 5 6}$ & $\mathbf{1 0 0}$ \\
\hline
\end{tabular}

Sumber : Kantor Desa Warembungan

Tabel 2 menunjukan bahwa sebagian besar penduduk Desa warembungan yangmengenyam pendidikan formal hanya mencapai tingkat SD dan SMP, sehingga perlu adanya usaha untuk mengerahkan pelajarpelajar di Desa Warembungan untuk mencapai tingkat pendidikan yang lebih tinggi. Sedangkan jumlah penduduk yang tidak mengenyam pendidikan formal, yaitu penduduk tidak sekolah, putus sekolah, belum memasuki masa sekolah atau hanya mendapatkan pendidikan non formal seperti les, kursus dan bimbingan belajar, jika diakumulasi bisa mencapai 1.559 Orang atau 33,78\% dari total keseluruhan penduduk.

\section{Penduduk Menurut Pekerjaan}

Pekerjaan atau mata pencaharian penduduk Desa Seadan Desa Warembungan berbeda-beda, dapat dilihat pada Tabel 3 dan Tabel 4

Tabel 3. Jumlah Penduduk menurut Angkatan Kerja di Desa Sea Tahun 2016

\begin{tabular}{clcc}
\hline No & $\begin{array}{c}\text { Mata } \\
\text { Pencaharian }\end{array}$ & Jumlah & $\begin{array}{c}\text { Persentase } \\
(\%)\end{array}$ \\
\hline 1 & Buruh Tani & 439 & 28.51 \\
2 & Petani & 387 & 25.13 \\
3 & Peternak & 35 & 2.27 \\
4 & Tukang Kayu & 22 & 1.43 \\
5 & Tukang Batu & 115 & 7.47 \\
6 & Penjahit & 18 & 1.17 \\
7 & P N S & 105 & 6.82 \\
8 & Pensiunan & 98 & 6.36 \\
9 & TNI/POLRI & 28 & 1.82 \\
10 & Perangkat & 23 & 1.49 \\
11 & Desa & 18 & 1.17 \\
12 & Pengrajin & 9 & 0.58 \\
13 & Buruh Industri Kecil & 243 & 15.78 \\
\hline Total & & $\mathbf{1 5 4 0}$ & $\mathbf{1 0 0}$ \\
\hline
\end{tabular}


Tabel 3 menunjukan bahwa sebagian besar penduduk Desa Sea bermata pencaharian sebagai petani dan buruh tani dengan persentase $53,64 \%$. Diikuti oleh penduduk bermata pencaharian sebagai buruh industri dengan persentase $15,78 \%$. Diikuti oleh penduduk yang bermata pencaharian sebagai tukang batu dengan persentase $7,47 \%$. Diikuti oleh penduduk yang bermata pencaharian sebagai PNS dengan persentase $6,82 \%$. Kemudian diikuti oleh penduduk yang bermata pencaharian sebagai pensiunan dengan persentase $6,36 \%$. Diikuti oleh penduduk yang bermata pencaharian sebagai peternak dengan persentase $2,27 \%$. Diikuti oleh penduduk yang bermata pencaharian sebagai TNI/POLRI dengan persentase $1,82 \%$. Diikuti oleh penduduk yang bermata pencaharian sebagai perangkat desa dengan persentase 1,49\%. Diikuti oleh penduduk yang bermata pencaharian sebagai tukang kayudengan persentase $1,43 \%$. Penduduk yang bermata pencaharian sebagai penjahit dan pengrajin yang jumlah persentasenya sama yaitu $1,17 \%$ kemudian diikuti oleh penduduk yang bermata pencaharian sebagai industri kecil dengan persentase $0,58 \%$.

Tabel 4. Jumlah Penduduk menurut Angkatan Kerja di Desa Warembungan

\begin{tabular}{llll}
\hline No & $\begin{array}{c}\text { Mata } \\
\text { Pencaharian }\end{array}$ & Jumlah & $\begin{array}{c}\text { Persentase } \\
(\%)\end{array}$ \\
\hline 1 & Petani & 2.622 & 83,34 \\
2 & P N S & 214 & 6,8 \\
3 & Wiraswasta & 43 & 1,36 \\
4 & Swasta & 151 & 4,79 \\
5 & TNI/POLRI & 22 & 0,7 \\
6 & Tukang bangunan & 81 & 2,57 \\
7 & Buruh & 13 & 0,41 \\
\hline TOTAL & 3.146 & 100 \\
\hline STL
\end{tabular}

Sumber : Kantor Desa Warembungan

Tabel 4 menunjukan bahwa jenis mata pencaharian mayoritas di Desa Warembunganadalah petani dengan total 2.622 orang atau 83,34 \%. Ini berbanding lurus dengan tingkat pendidikan penduduk yang mayoritas hanya mencapai tingkat SD, bahkan banyak juga yang tidak mengenyam pendidikan formal. Ini dikarenakan kemampuan bertani tidak perlu didapatkan dari bangku sekolah, melainkan hanya berdasarkan pada pengalaman dan pengetahuan yangdiwariskan turun temurun dari petani pendahulu.

\section{Penduduk Menurut Agama}

Agama dan kepercayaan yang dianut penduduk Desa Sea dan Desa Warembungan berbeda-beda dan dapat dilihat pada Tabel 5 dan Tabel 6.

Tabel 5. Jumlah Penduduk Menurut Agama di Desa Sea Tahun 2016

\begin{tabular}{llll}
\hline No & \multicolumn{1}{c}{ Agama } & Jumlah & Persentase \\
\hline 1 & Kristen Protestan & 2.572 & 53,42 \\
2 & Katolik & 858 & 17,82 \\
3 & Islam & 1.382 & 28,7 \\
4 & Hindu & 3 & 0,06 \\
\hline Total & & $\mathbf{4 . 8 1 5}$ & $\mathbf{1 0 0}$ \\
\hline
\end{tabular}

Tabel 5 di atas menunjukkan bahwa sebagian besar penduduk Desa Sea beragama Kristen Protestan dengan jumlah persentase $53,42 \%$ dengan jumlah penduduk sebanyak 2.572 jiwa dan agama Islam dengan jumlah persentase $28,7 \%$ dengan jumlah penduduk 1.382 jiwa dan diikuti oleh penduduk beragama Katolik dengan persentase $17,82 \%$ dengan jumlah penduduk 858 jiwa dan penduduk beragama Hindu dengan persentase $0,06 \%$ dengan jumlah penduduk 3 jiwa.

Tabel 6. Jumlah Penduduk Menurut Agama di Desa Warembumbugan Tahun 2012

\begin{tabular}{llll}
\hline No & \multicolumn{1}{c}{ Agama } & Jumlah & \multicolumn{1}{c}{ Persentase } \\
\hline 1 & Kristen Protestan & 2.249 & 48,73 \\
2 & Katolik & 1.790 & 38,79 \\
3 & Islam & 576 & 12,48 \\
\hline Total & $\mathbf{4 . 6 1 5}$ & $\mathbf{1 0 0}$ \\
\hline
\end{tabular}

Agama dan kepercayaan yang dianut penduduk Desa Warembungan terbagi atas 3 agama besar yaitu Kristen Protestan, Kristen katolik dan Islam. Tabel 6 di atas menunjukkan bahwa sebagian besar penduduk Desa Warembungan beragama Kristen Protestan dengan jumlah persentase $48,73 \%$ dengan jumlah penduduk 2.249 jiwa dan penduduk beragama Katolik dengan persentase 38,79\% jiwa dan agama Islam dengan jumlah persentase $12,48 \%$ dengan jumlah penduduk 576 jiwa 


\section{Karakteristik Responden}

\section{Umur Responden}

Umur sangat mempengaruhi seseorang baik cara berpikir maupun bekerja. Tabel 7 menunjukkan jumlah responden menurut umur.

\begin{tabular}{|c|c|c|c|c|c|c|}
\hline \multicolumn{7}{|c|}{ Tabel 7. Jumlah Responden menurut Kelompok Umur } \\
\hline No & $\begin{array}{c}\text { Kelompok } \\
\text { umur } \\
\text { (Tahun) }\end{array}$ & Orangtua & Anak & Orangtua & Anak & Total \\
\hline 1 & $<=15$ & - & 3 & - & 4 & 7 \\
\hline 2 & $16-25$ & - & 4 & - & 3 & 7 \\
\hline 3 & $26-35$ & 1 & - & - & - & 1 \\
\hline 4 & $36-45$ & 2 & - & 5 & - & 7 \\
\hline 5 & $46-55$ & 3 & - & 2 & - & 5 \\
\hline 6 & $56-65$ & 1 & - & - & - & 1 \\
\hline Tot & & 7 & & 7 & 7 & 28 \\
\hline
\end{tabular}

Tabel 7 menunjukkan bahwa sebagian besar responden orangtua petani berada pada kisaran umur 46-55 tahun yaitu sebanyak 3 responden.Diikuti kisaran umur 36-45 tahun yaitu sebanyak 2 responden. Diikuti kisaran umur 26-35 tahun dan 56-65 tahun dengan jumlah responden yang sama yaitu 1 responden. Kemudian sebagian besar responden anak petani berada pada kisaran umur 16-25 tahun yaitu sebanyak 4 responden kemudian diikuti kisaran umur $<=15$ tahun yaitu sebanyak 3 responden.

Responden orangtua non petani sebagian besar berada pada usia produktif yaitu kisaran umur 36-45 tahun yaitu sebanyak 5 responden dan diikuti kisaran umur 46-55 tahun yaitu sebanyak 2 responden. Kemudian sebagian besar responden anak non petani berada pada kisaran usia $<=15$ tahun yaitu sebanyak 4 responden dan diikuti oleh kisaran umur 16-25 tahun yaitu sebanyak 3 responden

\section{Jenis Kelamin Responden}

Tabel 8. Jumlah Responden menurut Jenis Kelamin

\begin{tabular}{lllllll}
\hline No & $\begin{array}{c}\text { Jenis } \\
\text { Kelamin }\end{array}$ & \multicolumn{2}{c}{ Orangtua } & Anak & \multicolumn{3}{c}{ Non-Petani } & Orangtua & Anak & \\
\hline 1 & Laki-laki & 3 & 3 & 2 & 7 & 15 \\
2 & Perempuan & 4 & 4 & 5 & - & 13 \\
\hline Total & & 7 & 7 & 7 & 7 & 28 \\
\hline
\end{tabular}

Dari Tabel 8 menunjukkan bahwa sebagian besar responden orangtua baik petani maupun non petani berjenis kelamin perempuan yaitu sebanyak 9 responden dan diikuti oleh jenis kelamin laki-laki yaitu sebanyak 5 responden.Kemudian sebagian besar responden anak baik petani maupun non petani yaitu dengan jenis kelamin laki-laki yaitu sebanyak 10 responden dan diikuti oleh jenis kelamin perempuan yaitu sebanyak 4 responden.

\section{Responden Petani dan Non Petani Menurut Tingkat Pendidikan Orangtua}

Pendidikan sangat penting dalam usaha peningkatan kualitas seseorang karena berguna dalam pembangunan pribadi serta peningkatan intelektual dan wawasan seseorang.

Tabel 9. Jumlah Responden Menurut Tingkat Pendidikan Orangtua di Desa Sea dan Desa Warembungan

\begin{tabular}{ccccc}
\hline No & Tamatan & Petani & Non Petani & Jumlah \\
\hline 1 & SD & 2 & 1 & 3 \\
2 & SMP & 5 & 5 & 10 \\
3 & SMA & - & 1 & 1 \\
\hline Total & & $\mathbf{7}$ & $\mathbf{7}$ & $\mathbf{1 4}$ \\
\hline
\end{tabular}

Dari Tabel 9 dapat dilihat bahwa orangtua baik petani maupun non petani memiliki tingkat pendidikan yang formal, dengan tingkat terbanyak yaitu SMP dengan jumlah 10 responden kemudian di tingkat SD sebanyak 3 responden dan di tingkat SMA sebanyak 1 responden.

\section{Responden Petani dan Non Petani Menurut Jumlah Anggota Keluarga}

Tabel 10. Jumlah Responden Menurut Jumlah Anggota Keluarga di Desa Sea dan Desa Warembungan

\begin{tabular}{ccccc}
\hline No & $\begin{array}{c}\text { Jumlah } \\
\text { Anggota }\end{array}$ & Petani & $\begin{array}{c}\text { Non } \\
\text { Petani }\end{array}$ & Jumlah \\
\hline 1 & 3 & 2 & - & 2 \\
2 & 4 & 4 & 2 & 6 \\
3 & 5 & - & 2 & 2 \\
4 & 6 & - & 2 & 2 \\
5 & 7 & - & - & - \\
6 & 8 & 1 & 1 & 2 \\
\hline Jumlah & & $\mathbf{7}$ & $\mathbf{7}$ & $\mathbf{1 4}$ \\
\hline
\end{tabular}

Dari Tabel 10 dapat dilihat bahwa sebagian besar jumlah anggota keluarga baik petani maupun non petani yaitu sebanyak 4 anggota keluarga dengan jumlah 6 responden. 
Diikuti dengan 3 anggota keluarga, 5 anggota keluarga, 6 anggota keluarga dan 8 anggota keluarga dengan jumlah 2 responden.

\section{Responden Menurut Jarak Tempat Tinggal dengan Sekolah}

Dari Tabel 11 dibawah menunjukkan bahwa jarak rumah dengan sekolah yang paling tinggi yaitu kisaran 1-2 kilometer dengan jumlah responden 10 orang, diikuti dengan jarak 100 meter, 2,5-3 kilometer, 3,5-4 kilometerdan 4,5-5 kilometer yaitu dengan jumlah responden yang sama yaitu 1 responden.

Tabel 11. Jumlah Responden Menurut Jarak Tempat Tinggal dengan Sekolah di Desa Seadan Desa Warembungan

\begin{tabular}{ccccc}
\hline No & Jarak & Petani & Non Petani & Jumlah \\
\hline 1 & $100 \mathrm{~m}$ & 1 & - & 1 \\
2 & $1-2 \mathrm{~km}$ & 5 & 5 & 10 \\
3 & $2,5-3 \mathrm{~km}$ & - & 1 & 1 \\
4 & $3,5-4 \mathrm{~km}$ & - & 1 & 1 \\
5 & $4,5-5 \mathrm{~km}$ & 1 & - & 1 \\
\hline Total & & $\mathbf{7}$ & $\mathbf{7}$ & $\mathbf{1 4}$ \\
\hline
\end{tabular}

\section{Responden menurut Jumlah Pendapatan Orangtua}

Pendapatan orangtua yaitu jumlah seluruh hasil pendapatan dari orangtua selama satu bulan.Pendapatan orangtua dapat dilihat pada Tabel 12.

\begin{tabular}{|c|c|c|c|c|}
\hline \multicolumn{5}{|c|}{$\begin{array}{l}\text { Tabel 12. Jumlah Responden menurut } \\
\text { Pendapatan Orangtua di Desa } \\
\text { Sea dan Desa Warembungan }\end{array}$} \\
\hline No & $\begin{array}{c}\text { Jumlah } \\
\text { Pendapatan } \\
\text { (Rp) }\end{array}$ & Petani & $\begin{array}{l}\text { Non- } \\
\text { Petani }\end{array}$ & Total \\
\hline 1 & $\begin{array}{c}500.000- \\
1.000 .000\end{array}$ & 2 & 1 & 3 \\
\hline 2 & $\begin{array}{l}1.100 .000- \\
2.000 .000\end{array}$ & 4 & 4 & 8 \\
\hline 3 & $\begin{array}{l}2.100 .000- \\
3.000 .000\end{array}$ & 1 & 2 & 3 \\
\hline Total & & 7 & 7 & 14 \\
\hline
\end{tabular}

Dari Tabel 12 diatas menunjukan bahwa sebagian besar responden orangtua memiliki pendapatan yang cukup tinggi yaitu dengan kisaran Rp. 1.100.00-Rp.2.000.000/bulan dengan jumlah responden 8 orang kemudian diikuti dengan kisaran pendapatan sebesar Rp.500.000-Rp.1.000.000/bulan dengan jumlah responden 3 orang.Diikuti dengan kisaran Rp. 2.100.000-Rp.3.000.000/bulan.

\section{Faktor-Faktor Penyebab Putus Sekolah antara Anak Petani dan Non-Petani Di Desa Sea dan Desa Warembungan Kecamatan Pineleng Kabupaten Minahasa}

\section{Faktor Internal}

Faktor-faktor penyebab putus sekolah pada anak petani dan non-petani dapat disebabkan oleh faktor internal atau faktor yang berasal dari dalam diri anak.Faktor penyebab putus sekolah karena faktor internal dapat di lihat pada Tabel 9.

Tabel 13.Alasan Putus Sekolah karena FaktorInternal di Desa Sea dan Desa Warembungan

\begin{tabular}{|c|c|c|c|c|c|c|}
\hline \multirow[t]{2}{*}{ No } & \multirow{2}{*}{$\begin{array}{c}\text { Alasan } \\
\text { Putus } \\
\text { Sekolah }\end{array}$} & \multicolumn{2}{|c|}{ Petani } & \multicolumn{2}{|c|}{ Non-Petani } & \multirow[t]{2}{*}{ Total } \\
\hline & & Orangtua & Anak & Orangtua & Anak & \\
\hline 1 & $\begin{array}{l}\text { Kemauan } \\
\text { Anak }\end{array}$ & 6 & 5 & 7 & 7 & 25 \\
\hline 2 & $\begin{array}{l}\text { Tidak } \\
\text { Menyukai } \\
\text { Sekolah }\end{array}$ & - & 1 & - & 2 & 3 \\
\hline Tot & & 6 & 6 & 7 & 9 & 28 \\
\hline
\end{tabular}

Dari Tabel 13 menunjukkan bahwa 6 responden orangtua petani dan 7 responden orangtua non petani memberikan alasan karena kemauan anak sehingga anak putus sekolah. Dari beberapa responden orangtua petani maupun orangtua non petani mengatakan bahwa anak sama sekali tidak mau lagi sekolah dengan berbagai macam alasan bahwa anak sering dipaksa sekolah dengan berbagai macam cara namun anak tetap tidak mau sekolah, dan juga ada anak yang lebih suka untuk bekerja dibanding dengan sekolah. Sedangkan 5 responden anak petani dan 7 responden anak non petani yang menjawab karena kemauan sendiri.

Dari Tabel 13 di atas juga menunjukkan bahwa ada 1 responden anak petani dan 2 responden anak non Petani yang memberikan alasan putus sekolah karena faktor tidak menyukai sekolah. Dari hasil penelitian, responden anak memberikan jawaban tidak menyukai sekolah karena anak merasa tidak 
nyaman dengan situasi di sekolah seperti cara mengajar guru di kelas dan juga mata pelajaran di kelas.

\section{Faktor Eksternal}

Faktor-faktor penyebab putus sekolah pada anak petani dan non-petani dapat disebabkan oleh faktor eksternal atau faktor yang berasal dari luar diri anak.Faktor penyebab putus sekolah karena faktor eksternal dapat di lihat pada Tabel 14.

Tabel 14.Alasan Putus Sekolah karena Faktor Eksternal di Desa Sea dan Desa Warembungan

\begin{tabular}{lllllll}
\hline No & $\begin{array}{c}\text { Alasan Putus } \\
\text { Sekolah }\end{array}$ & \multicolumn{2}{c}{$\begin{array}{c}\text { Petani } \\
\text { Orangtua }\end{array}$} & Anak & Orangtua & Anak \\
\hline 1 & $\begin{array}{l}\text { Kondisi } \\
\text { Ekonomi }\end{array}$ & 3 & 2 & 2 & 1 & 8 \\
2 & $\begin{array}{l}\text { Lingkungan } \\
\text { Sosial }\end{array}$ & 3 & 5 & 2 & 3 & 13 \\
\hline Total & $\mathbf{6}$ & $\mathbf{7}$ & $\mathbf{4}$ & $\mathbf{4}$ & $\mathbf{2 1}$ \\
\hline
\end{tabular}

Dari Tabel 14 menunjukkan bahwa ada 3 responden orangtua petani dan 2 responden orangtua non petani yang mengatakan bahwa faktor penyebab anak putus sekolah yaitu karena kondisi ekonomi.Dimana orangtua sudah tidak mampu membiayai anak untuk kebutuhan sekolah karena pendapatan orangtua rendah dan tingkat pendidikan juga rendah sehingga anak berhenti sekolah.Dua responden anak petani dan 1 responden anak non petani memberikan alasan putus sekolah karena kondisi ekonomi dari orangtua yang sudah tidak mampu membiayai kebutuhan sekolah.Dari beberapa responden anak mengatakan bahwa anak sering malu karena biaya sekolah sudah menumpuk.

Dari Tabel 14 menunjukkan bahwa 3 responden orangtua petani dan 2 responden orangtua non petani yang mengatakan bahwa alasan anak putus sekolah adalah pengaruh lingkungan. Dari beberapa responden orangtua baik petani maupun non petani mangatakan bahwa pengaruh lingkungan yang dimaksud yaitu anak terpengaruh dengan teman yang sudah tidak sekolah dan bergaul terlalu berlebihan, sehingga anak berhenti sekolah.5 responden anak petani dan 3 responden anak non petani memberikan alasan putus sekolah karena pengaruh lingkungan.Dari beberapa responden anak baik petani maupun non petani mengatakan bahwa pengaruh lingkungan yang dimaksud adalah anak ikut-ikutan teman yang sudah tidak sekolah, orangtua cerai (broken home), danbergaul berlebihan sehingga anak putus sekolah.

\section{Rekapitulasi Faktor-Faktor Penyebab Putus Sekolah antara Anak Petani dan Non Petani Di Desa Sea dan Desa Warembungan Kecamatan Pineleng Kabupaten Minahasa}

Hasil penelitian tentang faktor-faktor penyebab putus sekolah antara anak petani dan non petani menggunakan 4 indikator sebagai tolak ukur dalam penelitian ini, dimana masing-masing terbagi dalam 2 kategori yaitu petani dan non petani dan terbagi lagi menjadi 2 yaitu orangtua dan anak. Rekapitulasi hasil penelitian dapat dilihat pada Tabel 15 .

Tabel 15. Rekapitulasi Faktor-Faktor Penyebab Putus Sekolah Antara Anak Petani dan Non Petani Di Desa Sea dan Desa Warembungan Kecamatan Pineleng Kabupaten Minahasa

\begin{tabular}{lcccccc}
\hline No & $\begin{array}{c}\text { Alasan } \\
\text { Putus } \\
\text { Sekolah }\end{array}$ & Orangtua & Anak & Orangtua & Anak & \\
\hline 1 & $\begin{array}{c}\text { Kemauan } \\
\text { Anak }\end{array}$ & 6 & 5 & 7 & 7 & 25 \\
& & & & & & Total \\
\end{tabular}

$\begin{array}{lllllll}2 & \text { Tidak } & - & 1 & - & 2 & 3\end{array}$

Menyukai

Sekolah

$\begin{array}{llllllll}3 & \text { Kondisi } & 3 & 2 & 2 & 1 & 8\end{array}$

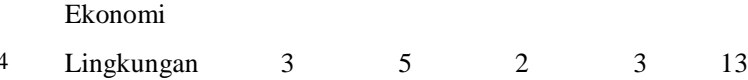

Sosial

\begin{tabular}{llllll} 
Total & 12 & 13 & 11 & 13 & 49 \\
\hline
\end{tabular}

Catatan: satu responden lebih dari satu jawaban

Tabel 15 menunjukkan bahwa dari 4 indikator, indikator yang ke 1 yaitu sebanyak 25 responden orangtua dan anak baik petani maupun non petani adalah penyebab yang paling tinggi terhadap terputus sekolahnya seorang anak baik petani maupun non petani dengan pernyataan bahwa alasan anak putus sekolah adalah kemauan anak, diikuti oleh indikator yang ke 4 yaitu sebanyak 13 responden orangtua dan anak baik petani maupun non petani, kemudiaan diikuti oleh indikator yang ke 3 yaitu kondisi ekonomi yaitu sebanyak 8 responden orangtua dan anak baik petani maupun non petani dan diikuti oleh indikator yang ke 2 yaitu tidak menyukai sekolah yaitu sebanyak 3 responden. 


\section{KESIMPULAN DAN SARAN}

\section{Kesimpulan}

1. Faktor-faktor penyebab putus sekolah antara anak petani dan non-petani di Desa Sea dan Desa Warembungan Kecamatan Pineleng Kabupaten Minahasa yaitu : faktor internal yang terdiri dari kemauan anak itu sendiri dan karena anak tidak menyukai sekolah. Faktor eksternal yang terdiri dari kondisi ekonomi orangtua (biaya) dan lingkungan sosial.

2. Ditingkat orang tua tidak ada perbedaan alasan putus sekolah. Sedangkan ditingkat anak terdapat perbedaan alasan putus sekolah yaitu anak non petani karena faktor internalyaitu: kemauan anak sendiri sedangkan anak petani karena faktor eksternal yaitu: lingkungan sosial. Artinya faktor penyebab putus sekolah anak non petani lebih dipengaruhi olehkemauan diri sendiri sedangkan anak petani lebih dipengaruhi oleh lingkungan.

\section{Saran}

1. Pemerintah mencari solusi yang terbaik kepada orangtua agar anak-anak yang putus sekolah lebih mengerti arti pentingnya suatu pendidikan.

2. Untuk orangtua, lebih mendekatkan diri kepada anak, membatasi cara bergaul anak dan memberikan pengertian kepada anak agar anak tertarik lagi dengan sekolah.

\section{DAFTAR PUSTAKA}

Astuti, R. M., dan Widowati, N., 2011. FaktorFaktor yang Memengaruhi Status Melanjutkan Pendidikan Pada Anak Usia 13-15 Tahun Di Desa/Kelurahan Pesisir Indonesia.Jurnal Aplikasi Statistika dan Komputasi Statistik,24.

Dewi, I. N., Zulkarnain, Z., dan Utami, R. K. S., 2014. Faktor-Faktor Penyebab Anak Lulusan SD Tidak Melanjutkan Ke SLTP. JPG (Jurnal Penelitian Geografi), 2(6)
Dhohiri, T. R. dkk. 2006. Sosiologi: Suatu Kajian Kehidupan Masyarakat.Jakarta: Yudhistira

Fatimah, S. 2015. Faktor-Faktor Penyebab Anak Putus Sekolah pada Jenjang Pendidikan Menengah (SMA/SMK) di Kecamatan Mijen Kota Semarang. (Doctoral dissertation, Universitas Negeri Semarang).

Fitria Yuli Rosandi. 2007. Pengaruh Kondisi Sosial Ekonomi Terhadap Motivasi Karanganyar Tahun 2007.Skripsi. Jurusan Geografi Fakultas Ilmu Sosial

Gunawan, Ary H., 2010. Sosiologi Pendidikan: Suatu Analisis Sosiologi tentang Pelbagai Problem Pendidikan.Jakarta: Rineka Cipta

Jumali, M dkk. 2008. Landasan Pendidikan. Surakarta: MuhammadiyahUniversity Press.

Lestari, D.2013 Pendidikan Karakter Aspek Tanggung Jawab Anak Pada Keluarga Petani (Studi Kasus Dukuh Purworejo Desa Mojokerto Kecamatan Kedawung Kabupaten Sragen Tahun 2013) (Doctoral dissertation, Universitas Muhammadiyah Surakarta).

Liansyah, L., dan Riva'ie, W., 2014. Analisis Faktor Penyebab Putus Sekolah Pada Jenjang Pendidikan SD di Desa Malikian Kecamatan Mempawah Hilir Kabupaten Pontianak.Jurnal Pendidikan dan Pembelajaran, 3(7).

Nasution S. 2004. Sosiologi Pendidikan. Jakarta: PT.Bumi Aksara

Setiawan, R., Hasyim, A., dan Yanzi, H., 2013. Faktor-Faktor yang Menyebabkan Remaja Desa Tidak Melanjutkan Pendidikan Kejenjang Sekolah Lanjutan.Jurnal Kultur Demokrasi, 1(8)

Stephen K. Sanderson. 2000. Makro Sosiologi, (Jakarta : PT Raja Gafindo Persada. 
Sudirman, N. 1989.Ilmu Pendidikan: Kurikulum,Program Pengajaran, Efek Instruksional dan Pengering, CBSA, Metode Mengajar, Media Pendidikan, Pengelolaan Kelas, Evaluasi Belajar. Bandung : Remaja Karya.

Sudjana, D. 2004. Pendidikan Nonformal : Wawasan, Sejarah Perkembangan, Falsafah dan Teori Pendukung, serta Azas. Bandung : Fallah Production.

Sutiasnah, R. A., 2014. Faktor-Faktor Penyebab Anak Putus Sekolah.Studi Madrasah Ibtidayah (MI) Dan Madrasah Tsanawiyah (MTs) Nurul Wathan Pusaran 8 Kecamatan Enok Kabupaten Indragiri Hilir.Jurnal Online Mahasiswa (JOM) Bidang Ilmu Sosial dan Ilmu Politik, 2(1), 1

Taha Z, Kaunang R. O, Ngiu Z., 2013., FaktorFaktor yang Menyebabkan Remaja Putus Sekolah di Desa Tabongo Kecamatan Dulupi Kabupaten Boalemo. KIM Fakultas Ilmu Sosial,1(1).
Titaley, M.E.E., 2012. Faktor-Faktor Penyebab Siswa Putus Sekolah pada Sekolah Menengah Pertama di SMP 4 dan SMP Taman Siswa Jakarta Pusat.Doctoral dissertation, Tesis.Universitas Indonesia.

Undang-Undang RI no. 20 tahun 2003 tentang Sistem Pendidikan Nasional14.Universitas Negeri Semarang.

Zainuri, M., H Matsum, J., \& Thomas, Y.2014.Tingkat Pendapatan, Sosial Budaya dan Jarak Rumah dengan Sekolah sebagai Faktor Penyebab Anak Putus Sekolah di SMPN.Jurnal Pendidikan dan Pembelajaran, 3(10). 